\title{
İpek Fibroin/Polivinil Alkol Esaslı İlaç Taşıyıcı Yara Örtüleri
}

\author{
Ayça BAL ÖZTÜRK*1,2® , Zeynep Püren AKGÜNER²® \\ 1İstinye Üniversitesi, Eczacıllk Fakültesi, Analitik Kimya Bölümü, 34010, İstanbul, Türkiye \\ 2̇̇stinye Üniversitesi, Sağlık Bilimleri Enstitüsü, Kök Hücre ve Doku Mühendisliği Bölümü, 34010, İstanbul, \\ Türkiye
}

\section{Anahtar Kelimeler}

İpek fibroin,

Polivinil alkol,

Yara örtüsü,

Hidrojel film,

Kontrollü salım
Özet: Bu çalışmanın amacl, potansiyel yara örtüsü olarak ilaç taşıyıcı-yeni bir karboksil modifiyeli poli(vinil alkol)-çapraz bağlı ipek fibroin esaslı hidrojel filmi (IF/PVA) geliştirmektir. Çapraz bağlı hidrojellerin hazırlanması için poli(vinil alkol) (PVA), karboksil modifiye poli(vinil alkol) (PVA-COOH) verecek șekilde süksinik anhidrit (SA) ile modifiye edilmiş, FTIR ve ${ }^{1} \mathrm{H}$ NMR analizleri ile karakterize edilmiștir. Takiben çözücü döküm yöntemi ile 1-etil-3-(3dimetilaminopropil) karbodiimid (EDC) ve n-hidroksisüksinimid (NHS) varlığında farklı konsantrasyonlarda PVA-COOH ve ipek fibroin (İF) esaslı bir seri hidrojel filmler hazırlanmıștır. Elde edilen filmlerin yapıları FTIR ve XRD analizleri ile karakterize edilmiş, yüzey morfolojileri optik mikroskop altında incelenmiş, şişme davranışları ve mekaniksel dayanım özellikleri belirlenmiştir. Gerçekleştirilen sitotoksisite testleri ile sentezlenen İF/PVA membran yara örtülerinin toksik olmadığı bulunmuștur. Optimum özelliklere sahip İF/PVA hidrojel filmine model ilaç olarak kuersetin yüklenmiş, etken madde yüklü filmlerin fosfat tamponu ortamında (pH:7,4) salım davranış profili incelenmiştir. Gerçekleștirilen in vitro yara modeli (çizik testi) sonuçları, 10 güne kadar kontrollü kuersetin salım profili gösteren İF/PVA filminin potansiyel ilaç taşıyıcı bir yara örtüsü olarak kullanılabileceğini göstermiștir.

\section{Silk Fibroin/Polyvinyl alcohol Based Drug Carrier Wound Dressings}

\section{Keywords}

Silk fibroin,

Polyvinyl alcohol,

Wound dressing,

Hydrogel film,

Controlled release

\begin{abstract}
The aim of this study was to develop a novel carboxyl modified poly(vinyl alcohol) - crosslinked silk fibroin based hydrogel film (IF/PVA) as a potential drug carrier wound dressing. For the preparation of crosslinked hydrogels, poly(vinyl alcohol) (PVA) was modified with succinic anhydride (SA) to give carboxyl modified poly(vinyl alcohol) (PVA-COOH) and characterized by FTIR and ${ }^{1} \mathrm{H}$ NMR analyzes. Subsequently, a series of hydrogel films based on different concentrations of PVA-COOH and silk fibroin (IF) were prepared in the presence of 1-ethyl-3-(3-dimethylaminopropyl) carbodiimide (EDC) and nhydroxysuccinimide (NHS) by solvent casting method. The structures of the synthesized films were characterized by FTIR and XRD analyzes and their surface morphology was examined under optical microscope and their swelling behavior and mechanical strength properties were determined. According to the performed cytotoxicity tests, it was found that the synthesized IF/ PVA membrane dressings were not toxic. The selected IF/PVA hydrogel film with optimum properties was loaded with quercetin as a model drug and their release profile was investigated in phosphate buffered media (pH: 7.4). The results of the in vitro wound model (scratch test) have shown that IF/PVA film showing a controlled quercetin release profile over 10 days can be used as a potential drug-carrier wound dressing.
\end{abstract}




\section{Giriş}

Deri dokusu; organları, enfeksiyonlara ve çevresel faktörlere karşı koruyarak bariyer görevi yapmaktadır. Bu nedenle; çeşitli kimyasal, mekanik, termal ve mikrobik ajanlardan doğrudan etkilenir. Yara örtüleri, cilt yaralanmalarının onarımı için potansiyel malzemelerdir. İdeal bir yara örtüsü, yara arayüzünde nemli bir ortam sağlamalı, hemostazı korumak için iyi bir sıvı tutma kapasitesine sahip olmalı, gaz değişimini sağlamalı ve mikroorganizmalara karşı koruyucu bir bariyer görevi görmelidir [1]. Hidrojeller, ideal yara örtüleri için gerekli özelliklere sahip olmaları nedeniyle diğer malzeme formlarına kıyasla en etkili seçimdir.

İpek, tekstil endüstrilerinde yüzyıllardır kullanılmaktadır. İpekböceği Bombyx mori'den elde edilen ipek proteini, serisin adı verilen yapıștırıcı benzeri bir protein ile bir arada tutulan iki fibroin proteinini içermektedir. Serisin proteini vücuda verildiğinde, $\mathrm{T}$ hücreleri tarafından antijenik bir faktör olarak algılanır ve immünolojik reaksiyonlara neden olmaktadır. Bu nedenle serisin proteini, zamk giderme (degumming) denilen bir prosesle koza liflerinden uzaklaştırılmalıdır. İpek fibroin, iyi derecede biyouyumluluk, geçirgenlik, kontrol edilebilir biyodegradasyon hızı, sulu çözeltilerde işlenebilirlik (böylelikle film, jel, toz gibi farklı formlarda kolaylıkla hazırlanabilme) gibi özelliklerinden dolayı ideal yara örtü materyallerinden biridir [2, 3]. Ayrica epidermal hücrelerin ve fibroblastların yapışmasını, yayılmasını ve çoğalmasını artırmakta ve yara iyileşmesini hızlandırmaktadır [1]. İpek fibroin esaslı doku mühendisliği iskeleleri (skafoldları), kontrollü ilaç taşıyıcı sistem matrisleri, yapay deri substitentleri ve yumuşak kontakt lensler gibi biyomateryallerin geliştirilmesinde de uygulama alanı bulmaktadır [4].

İpek fibroinin yukarıda sayılan avantajlarının yanı sıra, filmleri kuru formda zayıf ve kırılgandır. Isıtma, metanol içine daldırma, kesme, sodyum aljinat, selüloz ve kitosan gibi doğal polimerler ile veya poli(akrilamid), poli(vinil alkol), poli(etilen glikol) ve poli(etilen oksit) gibi sentetik polimerler ile harmanlama veya kimyasal olarak çapraz bağlama gibi çeşitli işlemlerle kolaylıkla modifiye edilerek özellikleri ayarlanabilmektedir [4,5]. Yaygın olarak kullanılan çapraz bağlayıcılar; glutaraldehit ve formaldehitler gibi aldehitler veya disikloheksil karbodiimid (DDC) ve 1-etil-3-(3dimetilaminopropil) karbodiimid hidroklorid (EDC) gibi karbodiimidlerdir. Literatürde, biyouyumlu çapraz bağlayıcılar olarak bilinen karbodiimidler; proteinler ve/veya polisakkaridlerden yapılan filmlerin özelliklerini iyileştirmek için kullanılmaktadır. Araştırmacılar genellikle hazırlanan filmlerin film oluşturma özelliklerini, esnekliklerini ve gerilme mukavemetlerini çapraz bağlandıktan sonra iyileştiğini rapor etmişlerdir [4]. Karbodiimidler ile çapraz bağlama yöntemi, yapıda bulunan primer aminleri karboksilik asitlerle reaksiyona sokarak bir amid bağı oluşumuyla sonuçlanan standart bir yöntemdir. $\mathrm{Bu}$ yöntem (karbodiimid kimyası) özellikle protein kimyasında geniş bir kullanım alanına sahiptir [6].

İpek fibroin filmleri özellikle, kristalizasyondan sonra, sert ve kırılgan formdadırlar. $\mathrm{Bu}$ özellikleri yara iyileştirme uygulamaları için yetersizdir $[7,8]$. PVA polimeri, mükemmel biyouyumluluk, ayarlanabilen fiziksel özellikler ve sulu çözeltilerde yüksek derecede şişme özellikleri nedeniyle çok tercih edilen bir materyaldir. Yara örtüsü, ilaç taşıyıcı sistemler ve yapay organlar gibi çeşitli ileri biyomedikal uygulamalarda kullanılmaktadır [9]. Bu çalışmada ipek fibroin filmlerinin özelliklerini iyileştirmek için, süksinik anhidrit (SA) ile modifiye edilen PVA polimeri (PVA-COOH) kullanılmıştır. İpek fibroinin mekaniksel dayanımını ve sudaki stabilitesini iyileştirmek için çapraz bağlanması gerekmektedir [5]. Bu nedenle literatürde ilk defa ipek fibroin ve PVA-COOH; çapraz bağlayıcı ajan olarak 1-etil-3-(3-dimetilaminopropil) karbodiimid (EDC) ve n-hidroksisüksinimid (NHS) varlığında çapraz bağlanmış (ipek fibroinin amin grupları ile PVA-COOH polimerinin karboksil grupları) ve geliştirilen hidrojel filmlerinin model ilaç varlığında yara örtüsü olarak kullanım potansiyelleri araştırılmıştır.

Etkili bir yara örtüsü, sargının sık değişmesini önlemek ve iyileşme sürecini hızlandırmak için kontrollü ilaç salımını uzun süre sürdürmelidir [9]. Bu kapsamda yara iyileștirme hızını artırmak için bir takım etken maddeler kullanılmaktadır. Flavonoidler, iyileştirme potansiyeli olan çok sayıda bitki özünde bulunan ana bileșenlerdir [10]. Kuersetin; anti-kanser, anti-ülser, anti-enflamatuar, anti-alerjik, anti-bakteriyel ve antiviral özellikler gösteren tipik bir flavonoiddir. Fibroblast proliferasyonunu artırdığı, immün hücre infiltrasyonunu azalttı̆ı bilinmektedir. Yapılan araştırmalar kuersetinin in vivo ve in vitro olarak yara iyileşmesinde fibrozis ve skar oluşumunu azalttığını göstermektedir $[11,12]$.

Bu çalışmada; çözücü döküm yöntemi ile EDC/NHS varlığında farklı konsantrasyonlarda PVA-COOH ve ipek fibroin (IF) esaslı bir seri hidrojel filmler (IF/PVA) sentezlenmiş ve FTIR, XRD, şişme testleri, mekaniksel dayanım, in vitro sitotoksisite ve çizik testi analizleri ile karakterize edilmiştir. Optimum özelliklere sahip IF/PVA hidrojeline model ilaç olarak kuersetin yüklenmiş ve salım profili incelenmiştir. Elde edilen sonuçlar, geliştirilen uzun süreli ilaç salım profili gösteren IF/PVA filminin potansiyel ilaç taşıyıcı bir yara örtüsü olarak kullanılabileceğini göstermiştir. 

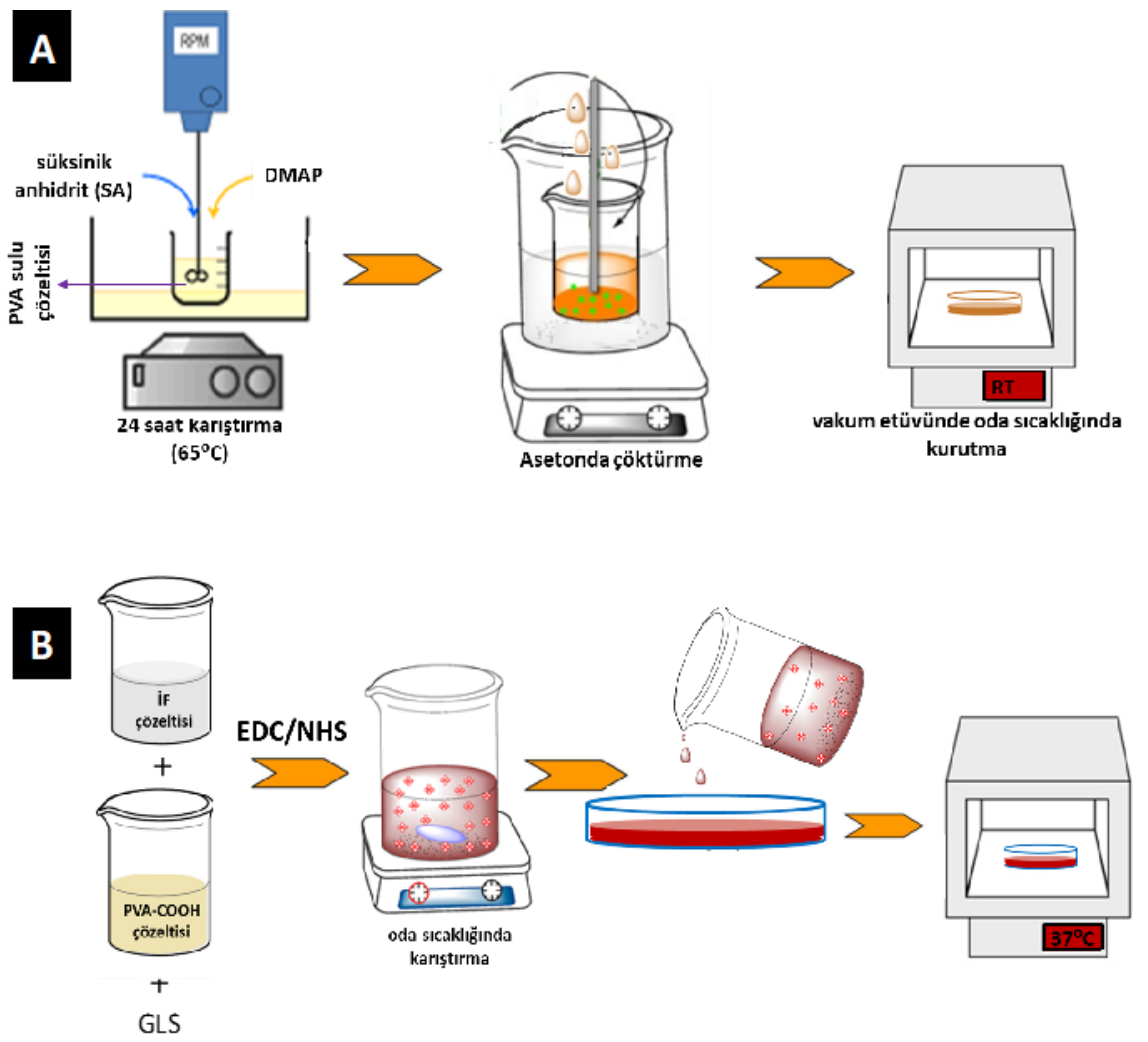

Şekil 1. (A) PVA-COOH polimerinin sentez aşamaları ve (B) İpek fibroin /PVA-COOH hidrojel filmlerinin üretim aşamaları

\section{Materyal ve Metot}

\section{1. İpek fibroin ekstraksiyonu}

Çalışmada kullanılan ipek böceği kozaları Bursa Koza Tarım Satış Kooperatifleri Birliği'nden (Kozabirlik) temin edilmiştir. İpek böceği kozaları bir makas yardımıyla küçük parçalara kesilerek yaklaşık 5 gram tartılmıştır. 0,02 M 2L NaCO 3 çözeltisinde yarım saat kaynatılmış, deiyonize su ile yıkandıktan sonra fazla suyu sıkılarak uzaklaștırılmıș ve oda sıcaklığında kurutulmuştur. Kurumuş üründen yaklaşık $1 \mathrm{~g}$ tartıldıktan sonra üzerine $4 \mathrm{~mL} \mathrm{9,3} \mathrm{M} \mathrm{LiBr} \mathrm{çözeltisi}$ ilave edilerek 4 saat süre ile bekletilmek üzere ön ısıtılmış $60^{\circ} \mathrm{C}$ etüve konmuştur. Bu süresinin sonunda elde edilen sarı renkli çözelti diyaliz membranına (MWCO=12000-14000 Da) alınarak distile suya karşı diyaliz edilmiştir. Elde edilen ürün santrifüj edilmiş ve $4^{\circ} \mathrm{C}$ de saklanmıştır [13]. Bu işlem sonrasında ağırlıkça \%7,5’luk İF çözeltisi elde edilmiştir.

\subsection{Karboksil sonlu PVA polimerinin sentezi (PVA-COOH)}

Ağırlıkça \%10’luk 100 mL PVA sulu çözeltisi hazırlanmıș ve çözelti $65^{\circ} \mathrm{C}$ 'ye isıtılmıştır. Çözeltiye, bu sıcaklıkta sürekli karıștırma altında 2,77 g 4dimetilaminopiridin (DMAP) ve 22,72 g süksinik anhidrit (SA yavaş yavaş eklenmiş ve reaksiyona 24 saat devam edilmiştir. Takiben elde edilen ürün oda sıcaklığına soğuduktan sonra asetonda çöktürülerek vakum etüvünde kurutmuştur (Şekil 1A). Beyaz renkli ürün elde edilmiştir. PVA-COOH yapısı ATR-
FTIR (Fourier Dönüşümlü Kızılötesi Spektroskopisi) ve ${ }^{1} \mathrm{H}$ NMR (Proton Nükleer Manyetik Rezonans Spektroskopisi) analizleri ile karakterize edilerek doğrulanmıştır. FTIR analizi 4000-500 $\mathrm{cm}^{-1}$ spektral aralığında Brucker marka Tensor II model ATR ünitesine sahip FTIR cihazı ile yapılmıştır. ${ }^{1} \mathrm{H}$-NMR analizleri çözücü olarak $\mathrm{D}_{2} \mathrm{O}$ kullanılarak Varian UNITY INOVA cihazl ile $(500 \quad \mathrm{MHz})$ gerçekleştirilmiştir.

\subsection{Hidrojel yara örtü filmlerinin hazırlanması}

Hidrojel yara örtüleri çözücü döküm tekniği kullanılarak hazırlanmıştır [14]. \%3'lük ipek fibroin ve \%5'lik PVA-COOH çözeltileri ve gliserin (GLS) belirli oranlarda karıștırılarak (Tablo 1) bir seri harman çözeltileri hazırlanmış, takiben belirli miktarlarda EDC ve NHS, çok kisa bir süre karıştırıldıktan sonra teflon petrilere dökülmüștür. $37^{\circ} \mathrm{C}$ de etüvde kurutulmuştur (Şekil 1B).

Tablo 1. İpek fibroin /PVA-COOH hidrojel filmlerinin bileșimi ve adlandırılması

\begin{tabular}{|c|c|c|c|c|c|}
\hline $\begin{array}{c}\text { Örnek } \\
\text { Kodu }\end{array}$ & $\begin{array}{c}\text { İpek } \\
\text { fibroin } \\
\text { çözeltisi } \\
\text { (mL) }\end{array}$ & $\begin{array}{l}\text { PVA- } \\
\text { COOH } \\
\text { çözeltisi } \\
\text { (mL) }\end{array}$ & $\begin{array}{c}\text { GLS } \\
\text { (mL) }\end{array}$ & $\begin{array}{l}\text { EDC } \\
(\mu g)\end{array}$ & $\begin{array}{l}\text { NHS } \\
(\mu \mathrm{g})\end{array}$ \\
\hline $0 \dot{\mathrm{IF}}$ & 0,00 & 10,0 & 1,0 & 10,0 & 10,0 \\
\hline $10 \dot{\mathrm{I} F}$ & 1,00 & 9,00 & 1,0 & 10,0 & 10,0 \\
\hline $20 \mathrm{IF}$ & 2,00 & 8,00 & 1,0 & 10,0 & 10,0 \\
\hline $30 \mathrm{IF}$ & 3,00 & 7,00 & 1,0 & 10,0 & 10,0 \\
\hline $50 \mathrm{IF}$ & 5,00 & 5,00 & 1,0 & 10,0 & 10,0 \\
\hline $70 \mathrm{IF}$ & 7,00 & 3,00 & 1,0 & 10,0 & 10,0 \\
\hline 100İF & 10,00 & 0,00 & 1,0 & 10,0 & 10,0 \\
\hline
\end{tabular}




\subsection{Hidrojel yara örtü filmlerinin karakterizasyonu}

Hazırlanan hidrojel yara örtü filmlerinin yapısı ATRFTIR analizi ile yapıları karakterize edilmiştir. Analiz Bölüm 2.2'de belirtildiği şekilde Brucker marka Tensor II model ATR ünitesine sahip FTIR cihazı ile gerçekleștirilmiştir. Yara örtü filmlerinin XRD analizleri, Rigaku marka XRD cihazında gerçekleştirilmiştir. Her filmden $2 \mathrm{~cm}^{2}$ lik parçalar kesilmiș ve $2 \theta=10-40^{\circ}$ aralığında tarama yapılmıștır. X-ışını kaynağı olarak $\mathrm{Cu} \quad \mathrm{K} \alpha \quad\left(\lambda=1.54 \quad \mathrm{~A}^{\circ}\right)$ kullanılmıştır. Filmlerin yüzey özellikleri ışık mikroskobu (Zeiss Stemi 5008) ile incelenmiştir. Hidrojel filmlerinin şişme davranışlarını belirlemek için gravimetrik yöntem kullanılmıştır [14]. Belirli tartımlardaki hidrojel filmleri $\mathrm{pH} 7,4$ fosfat tampon çözeltisine daldırılmış, 48 saatin sonunda filmlerin yüzeyindeki fazla su filtre kâğıdı ile uzaklaştırıldıktan sonra tekrar tartılmıştır. Filmlerin şişme özellikleri;

$$
\text { Şişme oranı }(\%)=\left(\mathrm{W}_{\mathrm{t}}-\mathrm{W}_{0} / \mathrm{W}_{0}\right) \times 100
$$

eşitliği ile belirlenmiştir. Bu eşitlikteki $\mathrm{W}_{0}$ ürünün kuru haldeki ağırlığı $W_{t} 48$ saat sonundaki ağırlığıdır. Filmlerin mekanik özellikleri, çekme-uzama testi Instron marka (Model: 3366 K 1630) Universal Test Cihazı kullanılarak incelenmiştir. Film örnekleri literatürde belirtildiği șekilde [8]. $10 \mathrm{mmx} 150 \mathrm{~mm}$ ebatlarında kesilerek cihazın çeneleri arasına tutturulmuş ve $10 \mathrm{~mm} /$ dakika hız ile çekilmiştir. Filmlerin çekme-uzama eğrileri, kopma anındaki uzama miktarları ve kopma anındaki gerilim değerleri belirlenmiştir.

\section{5. İlaç yükleme ve salım çalışmaları}

Gerçekleştirilen karakterizasyon sonuçlarına göre optimum özelliklere sahip (yüzey, şişme, mekaniksel dayanım) yara örtüsü formülasyonu belirlenmiştir. Bölüm 2.3.'de belirtilen prosedür kullanılarak (EDC/NHS ilavesinden önce polimer çözeltisine $2 \mathrm{mg}$ kuersetin ilave edilerek) kuersetin yüklü yara örtüsü hazırlanmıș ve elde edilen kuersetin yüklü yara örtüleri 30İF-K kodu ile isimlendirilmiştir. Kuersetin yüklü yara örtülerinin salım davranışları, belirli miktarda tartılan filmlerin in vitro şartlarda PBS çözeltisine (pH 7,4) daldırılarak belirli zaman aralıklarında salım ortamından alınan çözeltilerin UV-vis spektrofotometre cihazı (Genesys ${ }^{\mathrm{TM}} 10 \mathrm{~S}$ UVVis, Thermo Scientific) ile $375 \mathrm{~nm}$ de absorbans değerleri ölçülerek belirlenmiştir [14-15].

\subsection{Sitotoksisite testi}

$\mathrm{Bu}$ çalışmada indirekt MTT yöntemi kullanılmıştır [16]. Bu yöntem IS010993-5 standart test yönteminden uyarlanarak geliștirilen bir yöntemdir [16]. Çalışma kapsamında göbek kordonundan elde edilen Mezenkimal Kök Hücreler (MKH) kullanılmıştır. MKH'lar Liv Hospital'dan (Ulus, İstanbul) temin edilmiş olup, çalışmada kullanılan
MKH'ların pasaj numaraları 4-6'dır. MKH kültür ortamı olarak; \%10 Fetal Sığır Serumu (FBS), \%1 Penisilin-Streptomisin içeren Dulbecco's Modified Eagle's Medium (DMEM) ortamında $37^{\circ}{ }^{\circ} \mathrm{C}$ 'de $\% 5$ $\mathrm{CO}_{2}$ 'li ortamda $75 \mathrm{~cm}^{2}$ lik kültür kabında inkübe edilmiștir. Kültür ortamı iki günde bir değiştirilmiştir. MKH'lar \%80 yoğunluğa ulaştığında \%0.05 Tripsin/0.02 EDTA solüsyonu ile kültür kabından ayrılmış, takiben DMEM ile süspanse edilerek 1500 rpm de 5 dakika santrifüj edilmiştir. Besiyeri, pipet yardımıyla atıldıktan sonra hücreler DMEM ile süspanse edilmiş ve thoma lamı ile hücre sayımı yapılmıştır. MTT analizi için örneklerin her iki tarafı 30 dakika UV ışığı altında sterilize edilmiștir. Steril örneklerin üzerine $1 \mathrm{~cm}^{2} / \mathrm{mL}$ oranı ile $\mathrm{MKH}$ kültür ortamı ilave edilerek 24 saat $37^{\circ}{ }^{\circ} \mathrm{C}$ de $\% 5 \mathrm{CO}_{2}^{\prime} \mathrm{li}$ ortamda inkübe edilmiştir [16]. İnkübasyon periyodundan sonra örneklerin bulunduğu $\mathrm{MKH}$ kültür ortamı aynı miktarda DMEM ile seyreltilmiştir. MKH'lar, 96 kuyucuklu plakalara kuyucuk başına $5 \times 10^{3}$ hücre olacak şekilde ekilmiş, üzerine $200 \mu \mathrm{l}$ MKH kültür ortamı eklenmiș ve 1 gece $37^{\circ} \mathrm{C}$ 'da $\% 5$ $\mathrm{CO}_{2}$ 'li ortamda inkübe edilmiştir. Sonrasında kuyucuklardaki besiyeri, örneklerin inkübe edildiği besiyeri ile değiştirilerek 6 saat inkübe edilmiştir. İnkübasyondan sonra kuyucuk başına $200 \mu$ DMEM ve $20 \mu \mathrm{l}$ MTT solüsyonu $(20 \mu \mathrm{g} / \mathrm{ml}$, PBS ile seyreltilerek) eklenmiş ve 4 saat daha inkübe edilmiştir. İşlemin devamında, ortamdaki hücre kültür besiyeri $200 \mu \mathrm{l}$ DMSO ile değiștirilmiş ve 20 dakikalık bir inkübasyondan sonra mikroplaka okuyucu kullanılarak 570 nm'de okunmuştur.

\subsection{In Vitro yara iyileştirme etkinliği testi}

Örneklerin yara iyileştirme etkinlikleri "in vitro çizik testi" ile belirlenmiştir [4]. Yaklașlk 2x104 hücre bulunan 24 kuyucuklu plakalar konfluent duruma geldiğinde steril $200 \mu$ mikropipet ucu ile hafifçe çizilmiş (yarayı simüle etmek için) ve tüm hücresel artıklar PBS ile yıkama yapılarak uzaklaştırılmıştır. Örnekler MTT analizi ile aynı şekilde (Bölüm 2.3.) hazırlanmıştır. DMEM ile aynı șekilde inkübe edilerek hazırlanan steril örnek çözeltileri, hazırlanan 24 kuyucuklu plakalara ilave edilmiş $37^{\circ} \mathrm{C}^{\prime} \mathrm{de} \% 5 \mathrm{CO}_{2}^{\prime} \mathrm{li}$ ortamda inkübe edilmiştir. Belirli zaman aralıklarında $(0,24$ ve 48 saat) yara modelindeki kapanma miktarı (yaralı bölgeye hücrelerin çoğalma oranı) invert mikroskop (Nikon Eclipse TS2-Tokyo, Japonya) altında fotoğrafları çekilerek değerlendirilmiştir.

\section{Bulgular}

\subsection{PVA-COOH sentezi}

Karboksillenmiş PVA polimeri (PVA-COOH) eldesi için, PVA polimeri esterifikasyon reaksiyonu yoluyla SA ile modifiye edilmiştir. PVA-COOH polimerinin yapısı, Şekil 2'de gösterildiği gibi FTIR ve ${ }^{1} \mathrm{H}$ NMR spektrumu ile doğrulanmıştır. PVA ve PVA-COOH polimerlerinin FTIR spektrası, Şekil 2A 'da 
görülmektedir. PVA ve PVA-COOH polimerlerinin FTIR spektrası karşılaştırıldığında, her iki spektrumda da serbest - $\mathrm{OH}$ gruplarının gerilme titreșiminden ileri gelen $3000-3400 \mathrm{~cm}^{-1}$ bölgesinde geniş bir absorpsiyon band, $\mathrm{CH}$ gruplarının gerilme ve deformasyon titreşimlerinden ileri gelen $2898 \mathrm{~cm}^{-}$ 1 ve $1401 \mathrm{~cm}^{-1}$ de keskin pikler görülmektedir. PVA$\mathrm{COOH}$ polimerinin FTIR spektrumunda belirtilen absorpsiyon bantlarının dişında maksimumu 1710 $\mathrm{cm}^{-1} 1172 \mathrm{~cm}^{-1}$ ve $1640 \mathrm{~cm}^{-1}$ bulunan yeni piklerin ortaya çıktığı görülmektedir. Bu absorpsiyon pikleri sırasılyla ester bağlarındaki $\mathrm{C}=0$ ve $-\mathrm{CO}$ gruplarının gerilme titreşimleri ve karboksilik asit gruplarındaki $\mathrm{C}=0$ gerilme titreşiminden ileri gelmektedir. $\mathrm{Bu}$ durum esterifikasyon reaksiyonun istenildiği şekilde meydana geldiğini doğrulamaktadır [9]. PVA-COOH polimerinin ${ }^{1} \mathrm{H}$ NMR spektrumu, Şekil 2B 'de görülmektedir. SA'nın asidin metilen protonlarına atanan yaklaşık 2,4-2,6 ppm aralığındaki yeni iki pik (c ve d) SA'nın PVA 'ya aşılandığını teyit etmektedir $[9,17]$.

\subsection{Hidrojel yara örtü filmlerinin hazırlanması ve karakterizasyonu}

Çözücü döküm tekniği kullanılarak bir seri (0İF, 10İF, 20IF, 30IF, 50IF, 70İF ve 100IF) İF/ PVA-COOH içeren hidrojel filmleri hazırlanmıștır. IF oranı \%30'un üzerinde kullanıldığında homojen görünümlü filmler elde edilememiştir (50IF ve 70IF filmleri). Yapılan literatür araştırmasına göre bunun en büyük nedeni PVA'nın artan polimerizasyon derecesi (DP) ile düşük çözünürlüğe sahip olmasına ve İF molekülünün $\beta$ formundaki konformasyonuna atfedilmektedir [18, 19]. Tanaka ve arkadașları farklı kompozisyonlardaki IF/PVA filmlerinin yapısını incelemiş, PVA ve İF polimerlerinin birbirleriyle uyumsuz (incompatible) olduklarını rapor etmiştir [18]. Daha sonraki yıllarda Dai ve arkadaşları İF/PVA filmlerinde katkı olarak kullanılan GLS 'nin filmlerin yapısal davranışlarına etkisini incelemişlerdir. Yaptıkları araştırma filmlerinin yapısının belirli miktarda GLS ilavesi ile bir dereceye kadar değişebileceğini göstermiştir [19]. Ortamdaki GLS varlı̆̆l, iki polimer arasında etkileşimin meydana gelmesine neden olmaktadır. Bu etkileșimler; İF'in amid grupları-gliserinin hidroksil
grupları-PVA'nın hidroksil grupları arasında oluşan hidrojen bağlarıdır. Bu çalışmada hazırlanan İF/PVA filmlerinden 10IF, 20IF ve 30İF filmlerinde faz ayrımı gözlenmemiștir. Bunun nedeni sentez sırasında kullanılan GLS molekülü İF ve PVA filmleri arasında uyumlaştırıcı görevi görmesinden kaynaklanmaktadır. Şekil 3A'da 0İF, 10İF, 20İF, 30İF ve 100IF filmlerinin FTIR spektrası görülmektedir. İpek fibroinin yapısında, alpha heliks ve beta konformasyonu olmak üzere iki olası bileşim bulunmaktadır. Her iki konformasyon da belirgin karakteristik pikler vermektedir. $\beta$-konformasyonu; $1630 \mathrm{~cm}^{-1}$ (amit I), $1530 \mathrm{~cm}^{-1}$ (amit II), $1265 \mathrm{~cm}^{-1}$ (amit III) ve $700 \mathrm{~cm}^{-1}$ (amit V) bölgelerinde; alpha heliks-konformasyonu ise $1660 \mathrm{~cm}^{-1}$ (amit I), 1235 $\mathrm{cm}^{-1}$ (amit III) ve $650 \mathrm{~cm}^{-1}$ (amit V) bölgelerinde absorpsiyon pikleri vermektedir $[20,21]$. 100IF filminde $\% 100$ oranında yer alan ipek fibroin $\beta$ konformasyonundan kaynaklanan pikler $1538 \mathrm{~cm}^{-1}$ (amit II) ve $681 \mathrm{~cm}^{-1}$ (amit V) bölgelerinde; alpha heliks-konformasyondan kaynaklanan pikler ise 1654 $\mathrm{cm}^{-1}$ (amit I) ve $1240 \mathrm{~cm}^{-1}$ (amit III) bölgelerinde gözlenmiştir. 100 İF filminde $1538 \mathrm{~cm}^{-1}$ ve $1240 \mathrm{~cm}^{-1}$ de gözlenen keskin piklerin İF/PVA filmlerinde șiddetlerinin oldukça azaldığı görülmektedir. $\mathrm{Bu}$ durum IF ve PVA-COOH polimerleri arasında EDC/NHS ile kimyasal çapraz-bağlanmanın geçekleştiğine atfedilmiştir.

X-ıșını difraksiyonu, numunenin kristalinite derecesi hakkında bilgi almak için kullanılır [9]. İF/PVA membran yara örtülerinin X-ışını paternleri Şekil 3B 'de görülmektedir. PVA $2 \theta=19,8^{\circ}$ de bir adet difraksiyon piki vermektedir. İpek fibroininin ana kırınım pikleri ise sırasıyla $2 \theta=12,88^{\circ}$ (ipek-I yapısını gösterir) ve $20,11^{\circ}$ (ipek-II yapısını temsil eder) olarak ortaya çlkmaktadır $[19,20]$. İF/PVA filmlerinin XRD paternlerinin, saf ipek fibroin (100IF) ve saf PVA (0IF) filmlerine kıyasla bazı farklılıklar gösterdiği görülmüştür. İF ve PVA'nın yapısından kaynaklanan ana kırınım piklerinin birbiriyle örtüştüğü, filmlerde artan İF miktarı ile kırınım piklerinin tepe noktasının sağ tarafa doğru kaydığ görülmektedir. Sonuçlar, İF/PVA filmlerinin kırınım desenlerinde, her iki bileşenin eğrilerinin birbiri ile üst üste çakıştığını göstermiştir.
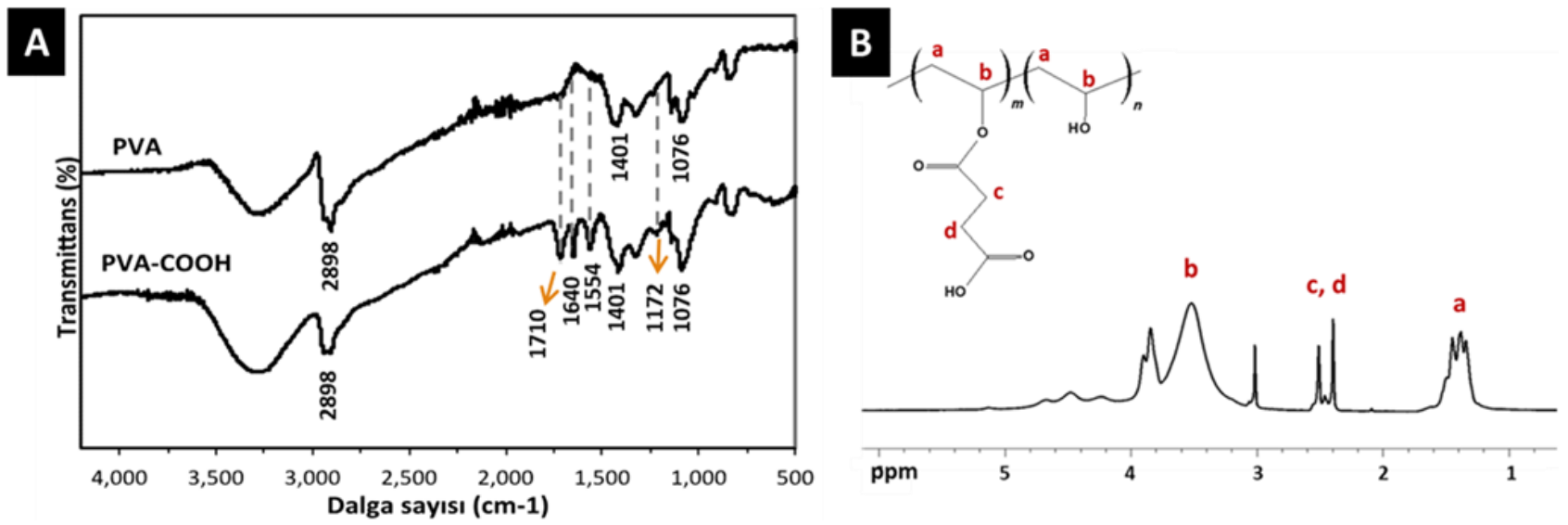

Şekil 2. (A) PVA ve PVA-COOH ürününün FTIR grafiği ve (B) PVA-COOH ürününün ${ }^{1} \mathrm{H}$ NMR grafiği 
A

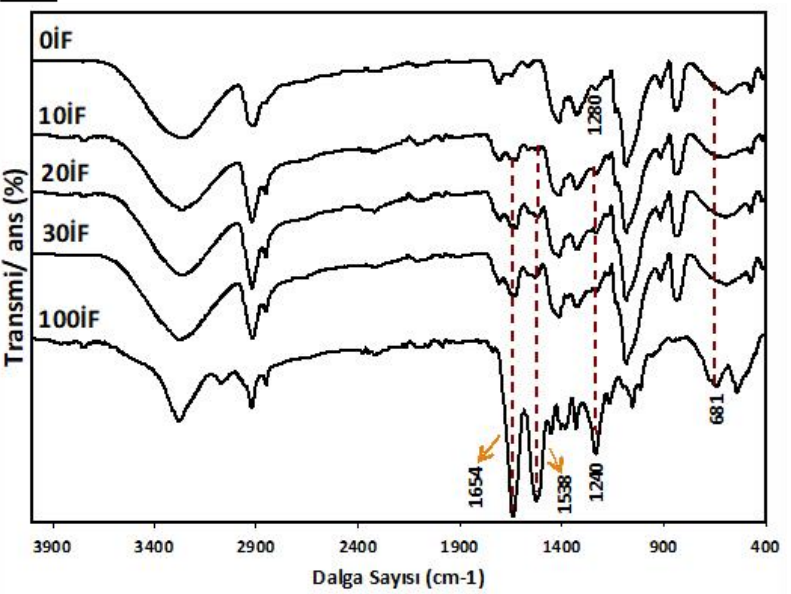

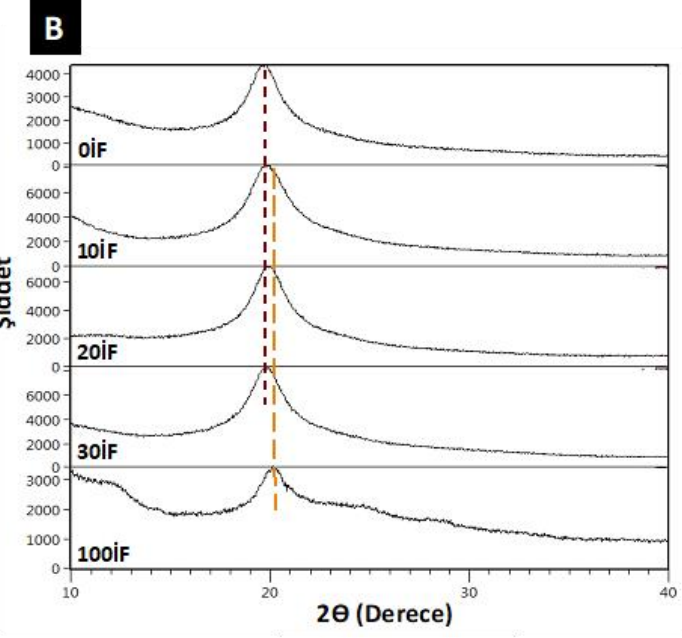

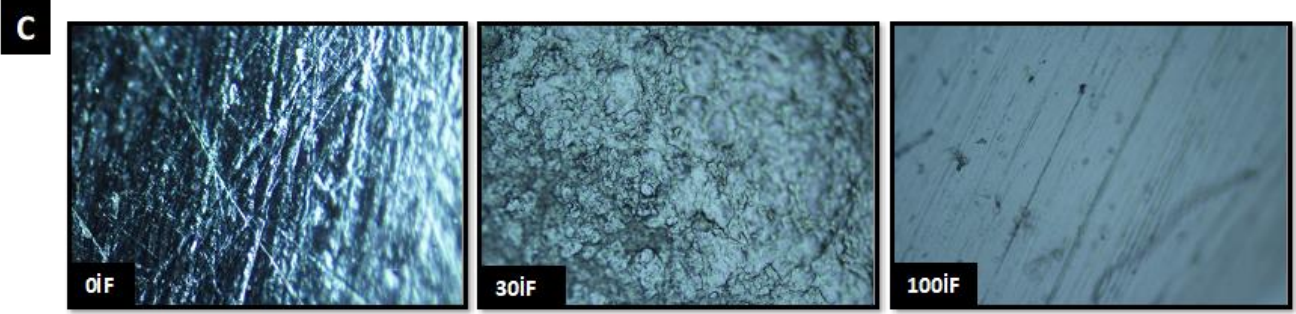

Şekil 3. İF/PVA membran yara örtülerinin (A) FTIR grafiği (B) XRD grafiği ve (C) optik mikroskop görüntüleri

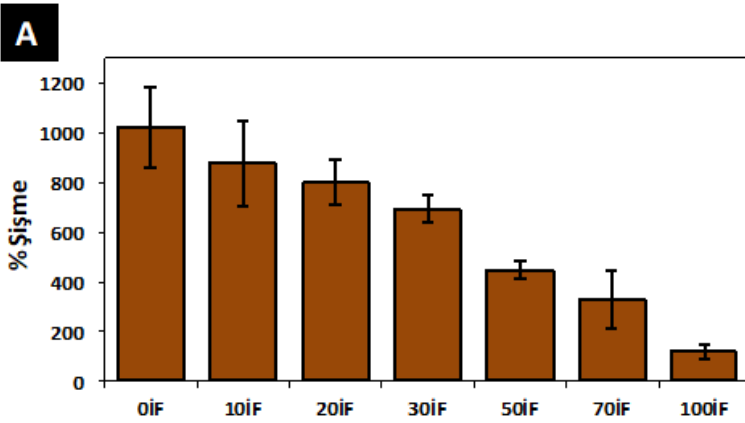

B

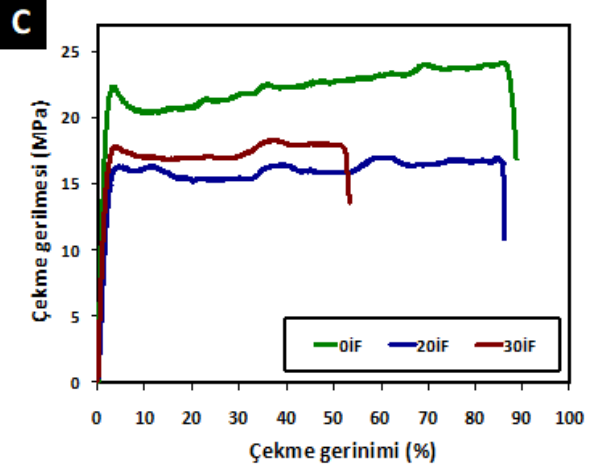

D
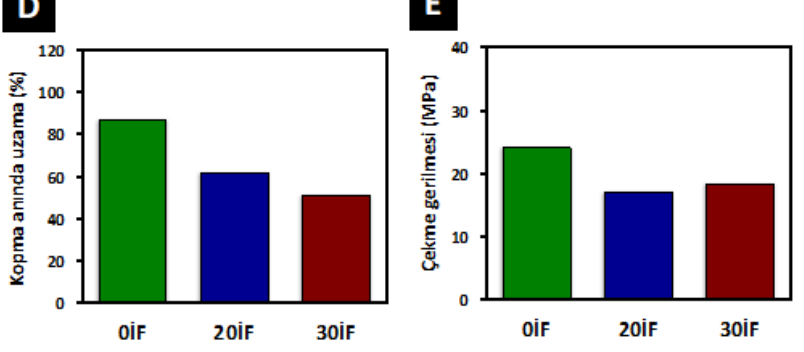

Şekil 4. (A) İF/PVA membran yara örtülerinin şişme sonuçları, (B) ilaç salım sonuçları, (C-E) mekaniksel dayanım sonuçları

Şekil 3C'de; 0İF, 30İF ve 100İF filmlerinin optik mikroskop altındaki görüntüleri görülmektedir. 30İF filminde herhangi bir faz ayrımı gözlenmemektedir. Yukarıda da açılklandığı üzere bunun temel nedeni sentez sırasında kullanılan GLS molekülünün uyumlaştırıcı görevi görmesinden kaynaklanmaktadır. Optik mikroskop görüntü sonuçları; PVA/İF filmlerinde yüksek İF oranlarında (>\%30IF) meydana gelen faz ayrışmasının GLS katkısıyla bir dereceye kadar geliştirilebildiğini doğrulamıştır [19]. Buna ek olarak; iki polimerin karıştırılmasıyla indüklenen kristalizasyon nedeniyle 30İF filminin üst yüzeyinin morfolojisinde pürüzler meydana gelmiştir [20].

Hazırlanan İF/PVA membran yara örtülerinin \% şişme değerlerini belirlemek için şişme deneyleri yapılmıştır. Şekil 4A'daki \% şişme değeri sonuçları, IF/PVA membran yara örtülerinin denge \% şişme değerlerinin \%1025-116 aralığında olduğunu 
göstermektedir. Tüm test edilen filmler arasında en yüksek \% şişme değerine sahip olan 0İF (\%1025); en düşük \% şişme değerine sahip olan filmi ise 100İF (\%116) olduğu bulunmuştur. Yapıda PVA miktarının artmasıyla birlikte filmlerin \% şişme değerlerinde artış gözlenmiştir. Bu durum yapıda bulunan PVA 'nın İF/PVA filmlerinin higroskopisitesini artırdığını göstermektedir. Tüm bu sonuçlar literatür ile uyumlu olup; İF/PVA fimlerindeki hidrofilik grupların sayısının artışıyla birlikte polimer-içi ve polimerlerarası zincir reaksiyonlarıyla oluşan esnek ağ yapıya atfedilebilir [22, 23].

Saf ipek fibroin filmlerinin (100ذ̇F) mekanik gücü zayıftır, kuru koşullarda kırılgan yapıdadırlar. Bu nedenle yara örtüleri olarak tek başlarına kullanımları uygun değildir. Daha iyi yara örtü performansı için mekanik özelliklerinin iyileştirilmesi gerekmektedir [24]. Bu dezavantajı ortadan kaldırmak için diğer polimerlerle birlikte kullanımları araştırılmaktadır. Bu çalışmada; yara iyileşme sürecini hızlandıran İF filmlerinin mekaniksel dayanımlarını iyileştirmek için PVA-COOH polimeri ile birlikte kullanımları araştırılmıştır. Farklı formülasyonlardaki IF/PVA filmlerinin (0IF, 20IF ve 30IF) gerilme mukavemeti ve kırılma noktasındaki uzamasını karakterize etmek için çekme testi uygulanarak gerilme-gerinim eğrileri çizilmiştir. Şekil 4C'de 0İF 20IF ve 30İF örneklerine ait gerilme-gerinim eğrileri görülmektedir. 100ذ் filminin kırılgan bir yapıda olması nedeniyle mekaniksel dayanım testi uygulanmamıştır. Beklendiği gibi, OİF filminin kırılma anındaki \%86,5'lik uzama değeri ile diğer karışım filmlerinden (20İF için \%61,75 ve 30İF için 51,27) daha esnek yapıda olduğu görülmektedir. (Şekil 4D). İF/PVA filmlerindeki IF miktarı arttıkça kırılma anındaki uzama değerinde düşüş gözlenmiştir. İF içeren ürünler (20İF ve 30ذ்) benzer gerilme dayanımları sergilerken, içermeyen örneklere kıyasla bir miktar düşüş söz konusu olup 30İF ürününün yara örtüsü olarak kullanımın (10İF ve 20İF filmlerine göre daha yüksek oranda ipek fibroin içermesi nedeniyle) daha uygun olduğu sonucuna varılmıştır.

Yüksek oranda PVA içeren İF/PVA membran yara örtüleri, daha fazla sıvı absorbe edeceğinden yara yatağını eksudanın birikmesinden koruyarak yara örtüsünün değişim sıklığını azaltacaktır [9]. Bunun yanında yapının ipek fibroin içermesi yaranın iyileşme hızını artıracaktır [25-28]. Tüm sonuçlar göz önüne alındığında en optimum formulasyonun $30 \dot{\mathrm{IF}}$ ürünü olduğu sonucuna varılmış ve ilaç yükleme ve salım çalışmaları için 30İF ürünü kullanılmıştır.

Etkili bir ideal yara örtüsü, sargının sık değişmesini önlemek ve iyileşme sürecini hızlandırmak için kontrollü ilaç salımını uzun süre sürdürmelidir [10]. Bu çalışmada; İF/PVA membran yara örtülerinin ilaç salım davranışlarını incelemek için model bir ilaç olarak kuersetin, kullanılmıștır. Kuersetin, Bölüm 2.5 'de belirtildiği şekilde $30 \dot{\mathrm{I} F}$ filmlerine sentez sırasında yüklenmiştir. Filmlerin salım davranışı fosfat tamponunda $(\mathrm{pH} \mathrm{7,4)}$ incelenmiştir. Kuersetin yüklü 30ÏF filmlerinden (30İF-K) zamana bağlı kuersetin salımı Şekil 4B'de verilmiştir. Sonuçlardan da anlaşılacağı üzere, 30İF-K filmi tipik bir bifazik ilaç salım davranışı sergilemiştir. Salımın birinci fazında patlama etkisi ile ilk 4 saatte kuersetinin yaklaşık \%23'ü salınırken (salınan toplam kuersetin miktarının yaklaşık \%50'si), patlama etkisini takiben uzatılmış bir salım gerçekleşmiştir. Kuersetin salımı yavaşlamış ve 8 gün içerisinde kuersetinin yaklaşık \%55 'si salınmıştır. Sonuçlar, uzun süreli ilaç salım profili gösteren 30İF filminin potansiyel bir yara örtüsü olarak kullanılabileceğini göstermiştir.

Klasik yara örtülerinin kullanım süreleri 1-3 gün arasında değişmektedir. Uzun süreli ilaç salım profili gösteren yara örtüleri ise yara bölgesinde etken maddenin salımını uzun sürede ve sürekli şekilde gerçekleștirdiklerinden sı sık yara örtüsünün değiştirilmesine olan ihtiyacı azaltmaktadır. Böylece yara bölgesinin ihtiyacından fazla ilaç ve malzeme kullanılmasının önüne geçilmiş olmaktadır [29]. Bu çalışmada geliştirilen uzun süreli ilaç salımı yapabilen yara örtüsü ile bir haftaya kadar değişim yapılmadan kullanılabilecek bir ürün geliştirilmiștir.

\subsection{Membran yara örtülerinin sitotoksisite testi sonuçları}

IF temelli malzemelerin biyouyumlu malzemeler oldukları hem in vitro hem in vivo hücre çoğalmasını ve büyümesini artırdıkları bilinmektedir [30-34].

Çapraz bağlanmıș IF/PVA membran yara örtülerinin biyouyumluluğu; MTT testi ile MKH'lar üzerinde Bölüm 2.6'da açıklandığı şekilde gerçekleştirilmiştir. IF/PVA membran yara örtülerinin sirasiyla (0ذंF, 10 IFF, 20 İF, $30 \dot{I} F$ ve $100 \dot{I} F) \% 106, \% 125, \% 132, \% 140$ ve $\% 163$; kuersetin yüklü 30İF-K filminin ise \%148 canlılık gösterdiği bulunmuştur. Sonuçlardan anlaşılacağı üzere, yapıdaki İF miktarı arttıkça \% hücre canlılığı artmaktadır (Şekil 5). Dolayısıyla yapıdaki İF miktarının artması kontrol gruplarına göre hücrelerin çoğalma hızlarını artırmaktadır.

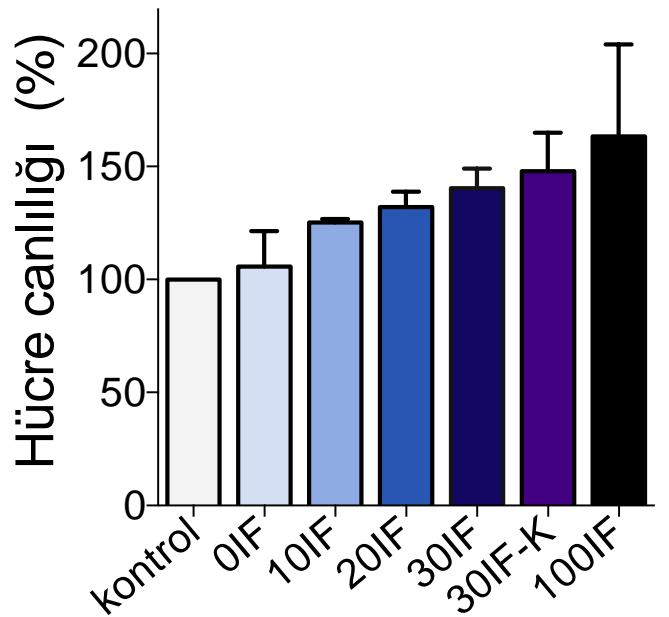

Şekil 5. İF/PVA membran yara örtülerinin hücre canlılı̆̆ sonuçları 
Kuersetin fibroblast proliferasyonunu arttırır, immün hücre infiltrasyonunu azaltır ve fibrozis ile ilișkili sinyalleme yolaklarında sinyallemede değişiklik yapmaktadır. Buna ek olarak, in vivo ve in vitro olarak yara iyileşmesinde fibrozis ve skar oluşumunu azalttığı bilinmektedir [11]. Bu bilgiler ıșığında; 30İF ve kuersetin yüklü $30 \dot{I} F$ filminin (30IF-K) sitotoksisite sonuçları karşılaştırıldığında, model ilaç olarak kullanılan kuersetinin hücrelerin çoğalma hızlarına 30İF filmine kıyasla çok daha fazla oranda artırdı̆̆ı görülmekte olup sonuçlar literatür ile uyumludur. Sonuç olarak, hazırlanan tüm filmlerin biyouyumlu olduğu ve başta yara örtüsü olmak üzere, doku mühendisliği ve rejeneratif tıp dahil birçok alanda kullanılabileceği düşünülmektedir.

\subsection{Membran yara örtü In Vitro yara iyileştirme etkinlikleri}

Geliștirilen İF/PVA membran yara örtülerinin mükemmel biyouyumluluğu, hidrojellerinin in vitro yara iyileştirme etkinliklerini araştırılmasına neden olmuştur. Yara modeli için steril $200 \mu$ pipet ucu kullanılmış ve MKH'ların konfluent tabakası üzerinde düz bir çizik oluşturulmuştur. Sonuçlar işlem sonrası yara modelindeki kapanma bakımından değerlendirilmiştir. Şekil 6'da 30İF ve 30İF-K filmlerine ait yara iyileştirme etkinliği (çizik testi) sonuçları görülmektedir. Sonuçlar, $30 \mathrm{I} F$ ve $30 \mathrm{I} F-K$ filmlerinin varlı̆̆ında kontrol grubuna karşı yara modelinin daha hızlı kapandığını göstermekte ve bu durum hücre göçü üzerinde olumsuz etkilerinin olmadığına işaret etmektedir. Geliştirilen 30ذ் filminin potansiyel ilaç taşıyıcı bir yara örtüsü olarak kullanılabileceği düșünülmektedir.

\section{Tartışma ve Sonuç}

$\mathrm{Bu}$ çalışmada; uzun süreli ilaç salımı yapabilen kuersetin yüklü İF/PVA membran yara örtüsü geliștirilmiştir. Çözücü döküm yöntemi ile EDC/NHS varlığında PVA/IF esaslı bir seri hidrojel filmler sentezlenmiş potansiyel ilaç taşıyıcı bir yara örtüsü olarak kullanılabilirliği araştırılmıştır. Filmlerin FTIR sonuçları, İF ve PVA-COOH polimerleri arasında EDC/NHS ile kimyasal çapraz-bağlanmanın gerçekleștiğini göstermiştir. Yapıda beklendiği gibi PVA miktarının artmasıyla birlikte \% şişme değerlerinde artış, İF miktarı arttıkça kırılma anındaki uzama değerinde düşüş gözlenmiștir. Sitotoksisite analizlerinde, yapıdaki artan İF miktarının \% hücre canlılığını olumlu yönde etkilediği görülmüştür. Bu sonuç, yapıdaki IF miktarındaki artışın kontrol gruplarına kıyasla hücrelerin çoğalma hızlarını artırdığı anlamına gelmektedir. Elde edilen sonuçlar ışığında, 30İF ürününün yara örtüsü olarak kullanımının (10ذ் ve 20İF filmlerine göre daha yüksek oranda ipek fibroin içermesi nedeniyle) daha uygun olduğu bulunmuştur. Takiben $30 \mathrm{IF}$ ürününe model ilaç olarak kuersetin yüklenmiş ve salım profili incelenmiştir. 30IF-K filmi tipik bir bifazik ilaç salım davranışı sergileyerek ilk 4 saatte yapısında sonrasında uzatılmış bir salım ile 8 gün içerisinde yaklaşık \%55 'sini salmıștır. Sonuçlar, kursetin yüklü 30İF filminin uzun süreli ilaç salım profil davranışına sahip olduğunu göstermiştir. 30İF ürününe ve $30 \mathrm{IF}-\mathrm{K}$ ürününe gerçekleştirilen in vitro yara modeli testi (çizik testi) sonuçları, geliştirilen ürünün potansiyel ilaç taşıyıcı bir yara örtüsü olarak kullanılabileceğini göstermiştir.
0. saat
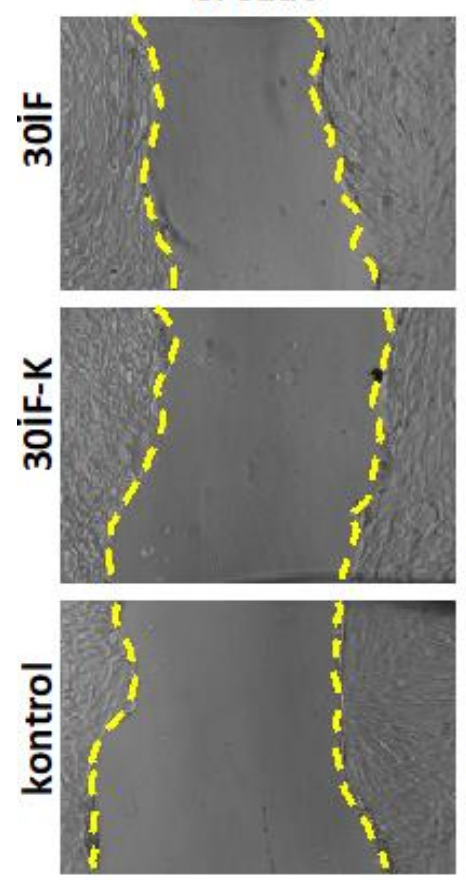

6. saat
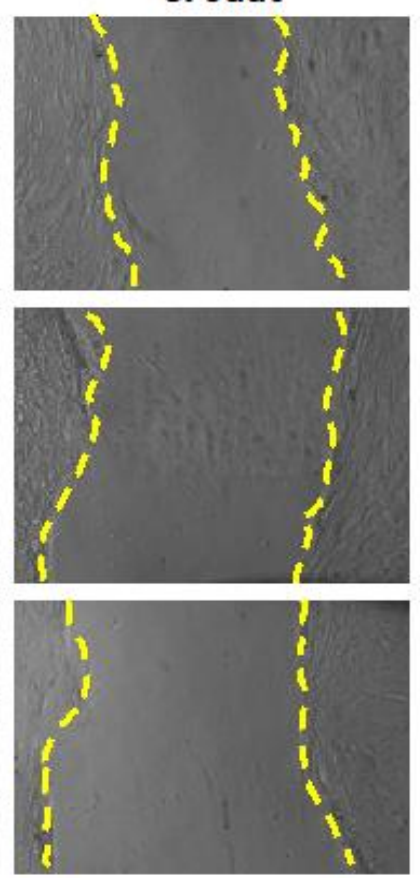

24. saat
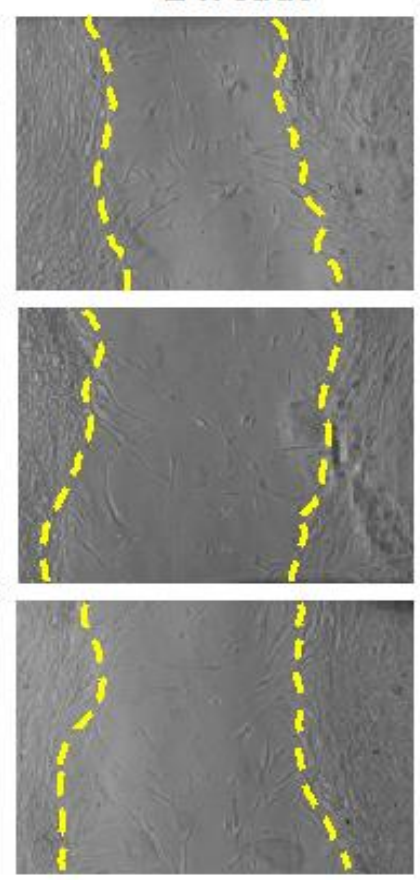

48. saat
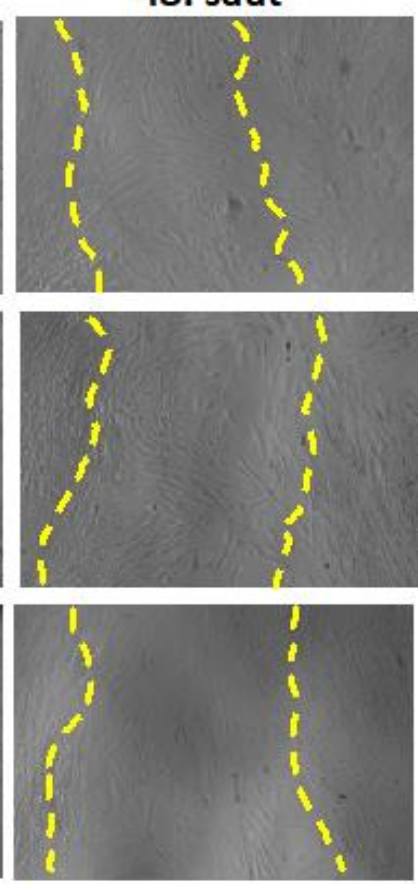

Şekil 6. İF/PVA membran yara örtülerinin (30İF ve 30İF-K) yara iyileştirme etkinliği (çizik testi) sonuçları 


\section{Kaynakça}

[1] Farokhi, M., Mottaghitalab, F., Fatahi, Y., Khademhosseini, A., Kaplan, D. L. 2018. Overview of silk fibroin use in wound dressings. Trends in biotechnology, 36(9), 907922.

[2] Çalamak, S., Erdoğdu, C., Özalp, M., Ulubayram, K. 2014. Silk fibroin based antibacterial bionanotextiles as wound dressing materials. Materials Science and Engineering: C, 43, 11-20.

[3] Guziewicz, N., Best, A., Perez-Ramirez, B., \& Kaplan, D. L. 2011. Lyophilized silk fibroin hydrogels for the sustained local delivery of therapeutic monoclonal antibodies. Biomaterials, 32(10), 2642-2650.

[4] Bayraktar, O., Malay, Ö., Özgarip, Y., Batıgün, A. 2005. Silk fibroin as a novel coating material for controlled release of theophylline. European Journal of Pharmaceutics and Biopharmaceutics, 60(3), 373-381.

[5] Wang, Y. X., Qin, Y. P., Kong, Z. J., Wang, Y. J., Ma, L. 2014. Glutaraldehyde Cross-Linked Silk Fibroin Films for Controlled Release. In Advanced Materials Research, 887, 541-546.

[6] Murphy, A. R., Kaplan, D. L. 2009. Biomedical applications of chemically-modified silk fibroin. Journal of materials chemistry, 19(36), 6443-6450.

[7] Panico, A., Paladini, F., Pollini, M. 2019. Development of regenerative and flexible fibroin-based wound dressings. Journal of Biomedical Materials Research Part B: Applied Biomaterials, 107(1), 7-18.

[8] Kundu, J., Mohapatra, R., Kundu, S. C. 2011. Silk fibroin/sodium carboxymethylcellulose blended films for biotechnological applications. Journal of Biomaterials Science, Polymer Edition, 22(46), 519-539.

[9] Zhang, D., Zhou, W., Wei, B., Wang, X., Tang, R., Nie, J., Wang, J. 2015. Carboxyl-modified poly (vinyl alcohol)-crosslinked chitosan hydrogel films for potential wound dressing. Carbohydrate polymers, 125, 189-199.

[10] Kant, V., Jangir, B. L., Nigam, A., Kumar, V., Sharma, S. 2017. Dose regulated cutaneous wound healing potential of quercetin in male rats. Wound Medicine, 19, 82-87.

[11] Vedakumari, W. S., Ayaz, N., Karthick, A. S., Senthil, R., Sastry, T. P. 2017. Quercetin impregnated chitosan-fibrin composite scaffolds as potential wound dressing materialsFabrication, characterization and in vivo analysis. European Journal of Pharmaceutical Sciences, 97, 106-112.
[12] Jangde, R., Srivastava, S., Singh, M. R., Singh, D. 2018. In vitro and In vivo characterization of quercetin loaded multiphase hydrogel for wound healing application. International journal of biological macromolecules, 115, 1211-1217.

[13] Rockwood, D. N., Preda, R. C., Yücel, T., Wang, X., Lovett, M. L., Kaplan, D. L. 2011. Materials fabrication from Bombyx mori silk fibroin. Nature protocols, 6(10), 1612-1631.

[14] Bashir, S., Teo, Y. Y., Ramesh, S., Ramesh, K. 2018. Synthesis and characterization of karaya gum-gpoly (acrylic acid) hydrogels and in vitro release of hydrophobic quercetin. Polymer, 147, 108120.

[15] Monjezi, J., Jamaledin, R., Ghaemy, M., Moeini, A., Makvandi, P. 2018. A Performance Comparison of Graft Copolymer Hydrogels Based on Functionalized-Tragacanth Gum/Polyacrylic Acid and Polyacrylamide as Antibacterial and Antifungal Drug Release Vehicles. American Journal of Nanotechnology \& Nanomedicine Research, 1(1), 010-015.

[16] Alavarse, A. C., de Oliveira Silva, F. W., Colque, J. T., da Silva, V. M., Prieto, T., Venancio, E. C., Bonvent, J. J. 2017. Tetracycline hydrochlorideloaded electrospun nanofibers mats based on PVA and chitosan for wound dressing. Materials Science and Engineering: C, 77, 271-281.

[17] Zhou, Z. F., Xu, W. B., He, D., Fan, J. X., Yu, F., Ren, F. M. 2007. Solid-state grafting of succinic anhydride onto poly (vinyl alcohol). Journal of applied polymer science, 103(2), 848-852.

[18] Tanaka, T., Tanigami, T., Yamaura, K. 1998. Phase separation structure in poly (vinyl alcohol)/silk fibroin blend films. Polymer international, 45(2), 175-184.

[19] Dai, L., Li, J., Yamada, E. 2002. Effect of glycerin on structure transition of PVA/SF blends. Journal of applied polymer science, 86(9), 2342-2347.

[20] Kundu, J., Mohapatra, R., Kundu, S. C. 2011. Silk fibroin/sodium carboxymethylcellulose blended films for biotechnological applications. Journal of Biomaterials Science, Polymer Edition, 22(46), 519-539.

[21] Kuzuhara, A., Asakura, T., Tomoda, R., Matsunaga, T. 1987. Use of silk fibroin for enzyme membrane. Journal of biotechnology, 5(3), 199-207.

[22] He, H., Cai, R., Wang, Y., Tao, G., Guo, P., Zuo, H., Xia, Q. 2017. Preparation and characterization of silk sericin/PVA blend film with silver nanoparticles for potential antimicrobial application. International journal of biological macromolecules, 104, 457-464. 
[23] Zhang, C. H., Yang, F. L., Wang, W. J., Chen, B. 2008. Preparation and characterization of hydrophilic modification of polypropylene nonwoven fabric by dip-coating PVA (polyvinyl alcohol). Separation and Purification Technology, 61(3), 276-286.

[24] Lee, K. H., Baek, D. H., Ki, C. S., Park, Y. H. 2007. Preparation and characterization of wet spun silk fibroin/poly (vinyl alcohol) blend filaments. International journal of biological macromolecules, 41(2), 168-172.

[25] Gil, E. S., Panilaitis, B., Bellas, E., Kaplan, D. L. 2013. Functionalized silk biomaterials for wound healing. Advanced healthcare materials, 2(1), 206-217.

[26] Vasconcelos, A., Gomes, A. C., Cavaco-Paulo, A. 2012. Novel silk fibroin/elastin wound dressings. Acta biomaterialia, 8(8), 3049-3060.

[27] Roh, D. H., Kang, S. Y., Kim, J. Y., Kwon, Y. B., Kweon, H. Y., Lee, K. G., Lee, J. H. 2006. Wound healing effect of silk fibroin/alginate-blended sponge in full thickness skin defect of rat. Journal of Materials Science: Materials in Medicine, 17(6), 547-552.

[28] Liu, T. L., Miao, J. C., Sheng, W. H., Xie, Y. F., Huang, Q., Shan, Y. B., Yang, J. C. 2010. Cytocompatibility of regenerated silk fibroin film: a medical biomaterial applicable to wound healing. Journal of Zhejiang University Science B, 11(1), 10-16.
[29] Kurtoğlu, A. H., Karataş, A. 2009. Yara tedavisinde güncel yaklaşımlar: modern yara örtüleri. Ankara Ecz. Fak. Derg., 38 (3), 211-232.

[30] Park, Y. R., Sultan, M. T., Park, H. J., Lee, J. M., Ju, H. W., Lee, O. J., Park, C. H. 2018. NF- $\kappa B$ signaling is key in the wound healing processes of silk fibroin. Acta biomaterialia, 67, 183-195.

[31] Park, Y. R., Ju, H. W., Lee, J. M., Kim, D. K., Lee, 0. J., Moon, B. M., Park, C. H. 2016. Threedimensional electrospun silk-fibroin nanofiber for skin tissue engineering. International journal of biological macromolecules, 93, 1567-1574.

[32] Park, H. J., Lee, O. J., Lee, M. C., Moon, B. M., Ju, H. W., min Lee, J., Park, C. H. 2015. Fabrication of 3D porous silk scaffolds by particulate (salt/sucrose) leaching for bone tissue reconstruction. International journal of biological macromolecules, 78, 215-223.

[33] Lee, D. H., Tripathy, N., Shin, J. H., Song, J. E., Cha, J. G., Min, K. D., Khang, G. 2017. Enhanced osteogenesis of $\beta$-tricalcium phosphate reinforced silk fibroin scaffold for bone tissue biofabrication. International journal of biological macromolecules, 95, 14-23.

[34] Lee, M. C., Kim, D. K., Lee, O. J., Kim, J. H., Ju, H. W., Lee, J. M., Park, C. H. 2016. Fabrication of silk fibroin film using centrifugal casting technique for corneal tissue engineering. Journal of Biomedical Materials Research Part B: Applied Biomaterials, 104(3), 508-514. 